\title{
Temporal dynamics of Human mastadenovirus species in cases of respiratory illness in southern Brazil
}

\author{
Viviane Girardi ${ }^{1}$ (D) $\cdot$ Tatiana Schäffer Gregianini $^{2}$ • Juliana Schons Gularte ${ }^{1} \cdot$ Meriane Demoliner $^{1}$. \\ Claudete Farina Seadi ${ }^{2} \cdot$ Selir Maria Straliotto ${ }^{2} \cdot$ Letícia Garay Martins $^{3} \cdot$ Fernando Rosado Spilki $^{1}$
}

Received: 10 January 2019 / Accepted: 12 April 2019 / Published online: 27 April 2019

(C) Sociedade Brasileira de Microbiologia 2019

\begin{abstract}
Human mastadenovirus (HAdV) genus is related to several diseases, among them upper and lower respiratory tract illness. HAdV species B, C, D, and E are mainly associated with respiratory infections. The goal of this work was to identify the HAdV species associated with respiratory infections in hospitalized patients from southern Brazil. Samples were collected from 1996 to 2004 and 2011 to 2017. During this period, 28,524 samples were collected, and 9983 were positive for respiratory viruses, being 435 for HAdV. From these 435 samples, 57 were selected for characterization of HAdV species. For screening the presence of HAdV, a partial sequence of the DNA polymerase gene (DNApol gene) was amplified by nested PCR. Partial nucleotide sequencing was performed in positive samples, and HAdV (DNApol gene) was detected in 53 samples: species B (28; $49.1 \%), \mathrm{C}(16 ; 28.0 \%), \mathrm{D}(2 ; 3.5 \%)$, E (5; 8.7\%), and untyped $(2 ; 3.5 \%)$. Specie D was found only in 2017 and specie E in 2011 and 2012. The age of the patients ranged from $<1$ to 81 years old, and $62.3 \%$ were male. No relationship between gender or age and identified HAdV species were observed. In addition, in the period of 2013-2017, 18 samples from patients who died were analyzed: 11 were related to species B, 4 to C, and 2 to D and 1 remained untyped. Circulation of HAdV species D and E varied over the years, but species $\mathrm{B}$ and $\mathrm{C}$ were present throughout the evaluated period. In addition, respiratory infections by HAdV affect elderly and children mainly.
\end{abstract}

Keywords Respiratory infections $\cdot$ Human mastadenovirus $\cdot$ HAdV-D $\cdot$ HAdV-E $\cdot$ Nested PCR

\section{Introduction}

Respiratory infections are worldwide responsible for high morbidity and a risk of mortality; children aged between 6 and 24 months are the most affected, while cases decline after this age, emphasizing that the lower the age group, the greater the number of hospitalizations [1-3]. In Brazil, specifically in

Responsible Editor: Giliane Souza Trindade.

Viviane Girardi

0178103@feevale.br

1 Laboratório de Microbiologia Molecular, Universidade Feevale, ERS 239 no. 2755, Novo Hamburgo, RS 93352-000, Brazil

2 Laboratório Central da Secretaria de Saúde do Estado do Rio Grande do Sul, LACEN/SES-RS, Av. Ipiranga, 5400, Porto Alegre, RS 90610-000, Brazil

3 Centro Estadual de Vigilância em Saúde da Secretaria de Saúde do Estado do Rio Grande do Sul-CEVS/SES-RS, Av. Ipiranga, 5400 , Porto Alegre, RS 90610-000, Brazil the state of Rio Grande do Sul (RS), the southernmost province of the country, respiratory diseases are considered a public health problem, mainly due to meteorological factors, since the winter of this region is characterized by sudden falls in temperature and intense humidity $[4,5]$.

The pathogens often associated with respiratory infections are viruses and bacteria, and viral etiological agents are in the first place [6]. Among the viruses that infect the respiratory tract Human mastadenovirus (HAdV) are frequent. Although most infections caused by these viruses are asymptomatic, HAdV can cause diseases such as pneumonia and bronchitis and when happening in immunocompromised patients, children and elderly, these infections may represent a risk of severe diseases [7-10]. HAdVs associated with respiratory infections are normally typed as B, C, D, and E species, being HAdV-C most commonly seen in young children $[11,12]$. These HAdV species have been reported in different countries such as Brazil [13], the USA [12], Taiwan [10], China [14], and Italy [15]. The goal of the present study was to identify the HAdV species associated with respiratory infections in 
hospitalized patients in different cities of the state of Rio Grande do Sul-Brazil.

\section{Material and methods}

\section{Sampling and demographics data}

A total of 57 samples were selected from 435 positive samples for HAdV for molecular characterization of HAdV species. The nasopharyngeal secretions from hospitalized patients with respiratory infection were collected in periods from 1996 to 2004 and 2011 to 2017 in RS. Previous analyses in 28,524 samples were performed to detect influenza virus (FLUV) at LACEN-RS (a Reference Laboratory of Public Health that belongs to the Brazilian network of Influenza and Other Respiratory Virus Surveillance and performs analyses of respiratory infections in Rio Grande do Sul, Brazil), and all samples included in the present work showed negative for FLUV. Subsequently, a screening for HAdV, hRSV (human respiratory syncytial virus), and hPIV 1, 2, and 3 (human parainfluenza virus) was carried out, and the samples HAdV-positive were sent to the Laboratory of Molecular Microbiology-University Feevale for the identification of HAdV species. In this study, we selected: (I) all available and biologically viable samples from 1996 to 2004; (II) a sampling in order to represent different municipalities of RS state and different epidemiological weeks from 2011 to 2017, and (III) all 18 fatalities occurred from 2013 to 2017.

The clinical and demographic characteristics of patients were obtained from compulsory notification forms, and because modifications in these forms occurred along the years, some information was available for a limited number of cases and some variables had missing values. In addition, data from 1996 to 2002 were obtained on records from LACEN-RS notebooks, before implementation of the epidemiological surveillance information system.

All experiments were performed in compliance with laws and institutional guidelines and in accordance with the ethical standards of the Declaration of Helsinki; this study was approved by the Research Board and Ethics Committee of Fundação Estadual de Produção e Pesquisa em Saúde do Estado do Rio Grande do Sul (FEPPS/SES-RS), Protocol 06/2004. All data were analyzed and reported anonymously and kept confidential.

\section{Extraction of genetic material and viral detection}

Nucleic acids were extracted with a BioPur® Kit from an initial volume of $200 \mu \mathrm{L}$ according to the instructions described by the manufacturer. The final elution was performed in microtubes free of DNAse/RNAse, in which they were stored and maintained at $-80^{\circ} \mathrm{C}$ until further viral detection.
For screening, the presence of HAdV species, a partial sequence of the DNA polymerase gene was amplified by nested PCR Measurements of the reaction were carried out for a final volume of $50 \mu \mathrm{L}$, as follows: $1 \mu \mathrm{L}$ of Pol-F primer (5'-CAGCCKCKGTTRTGYAGGGT-3), $1 \mu \mathrm{L}$ primer Pol-R (5'-GCHACCATYAGCTCCAACTC-30), both primers at 20 pmoles, $18 \mu \mathrm{L}$ DNAse/RNAse free water, $25 \mu \mathrm{L}$ GoTaq ${ }^{\circledR}$ Colorless Master Mix (Promega, USA), and $5 \mu \mathrm{L}$ nucleic acid extracted, also positive and negative controls were included. After initial incubation at $94{ }^{\circ} \mathrm{C}$ for $5 \mathrm{~min}, 30$ cycles of amplification were performed. These consisted of denaturation at $94{ }^{\circ} \mathrm{C}$ for $30 \mathrm{~s}$, annealing at $48^{\circ} \mathrm{C}$ for $30 \mathrm{~s}$, extension at $72^{\circ} \mathrm{C}$ for $30 \mathrm{~s}$, and a final extension at $72{ }^{\circ} \mathrm{C}$ for $10 \mathrm{~min}$. Amplification was performed in a Bio-Rad® thermal cycler. The second PCR reaction was performed using the same reagents and quantities from the first one, and the same amplification cycles carried out with the products of the first PCR; however, both primers were replaced with Pol-nF (50GGGCTCRTTRGTCCAGCA-30) and Pol-nR (50TAYGACATCTGYGGCATGTA-30) [16]. PCR products were analyzed on $2 \%$ agarose gel; $0.5 \mathrm{mg}$ of ethidium bromide $/ \mathrm{mL}$ was added and the running time was $60 \mathrm{~min}$ at $70 \mathrm{~V}$. Molecular sizes of the products were compared with a 100 bp DNA standard (Ludwig brand). The bands stained with ethidium bromide were visualized in UV light; subsequently, images were photographed with Easy Doc 200 UV transilluminator equipment.

Positive samples by nested PCR were submitted to sequencing for species identification. PCR products (261 bp) were purified before sequencing with PureLink ${ }^{\mathrm{TM}}$ Quick Gel Extraction and PCR Purification Combo Kit (Invitrogen $®$ ), according to the instructions described by the manufacturer. Sequencing was performed by Ludwig Biotec (Sequencing Service) using an automated sequencer (ABI-PRISM 3500 Genetic Analyzer Applied Biosystems). Phylogenetic analysis was performed by comparing the genomic sequences obtained by direct DNA sequencing with other nucleotide fragments available from GenBank, by Neighbor-Joining methodology [17]. A phylogenetic tree was elaborated from the calculation of evolutionary distances, using the Kimura-parameter 2 method [18] and operating with Molecular Evolutionary Genetics Analysis software version 5 (MEGA5) [19].

\section{Results}

\section{Evaluation of the presence of HAdV by species and by year of sampling}

In a total of 57 samples evaluated from hospitalized patients, HAdV DNApol gene was detected in 53 samples (Fig. 1). Different HAdV species were identified: HAdV species B (28; 49.1\%), C (16; 28.0\%), D (2; 3.5\%), and E $(5 ; 8.7 \%)$ 


\section{3}

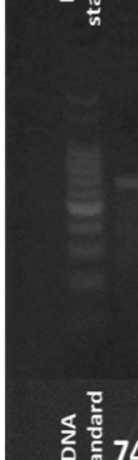

崖 74 576 7677 7879 7980
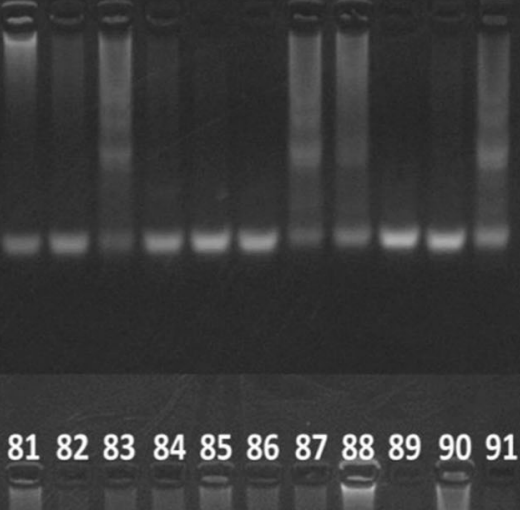

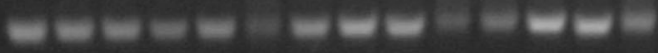

\section{(1)}

Fig. 1 Gels from some samples of patients with respiratory infection associated with Human mastadenovirus (HAdV) showing specific amplicons with the expected size in positive samples. DNA standard, $100 \mathrm{bp} ; \mathrm{C}+$, positive control; $\mathrm{C}-$, negative control

(Figs. 2a and 3). It is observed, circulation of species D and E over the years, since the species $\mathrm{D}$ was detected only in the year 2017 and the species E only in 2011 and 2012. The B and $\mathrm{C}$ species were present throughout the period evaluated. It was not possible to identify the specie in two previously positive samples in the nested PCR due to the low quality of the DNA sequence.

The seasonality of the cases of infection for HAdV, considering the 435 positive patients of the analyzed period, shows that HAdV infections occur throughout the year (Fig. 2b) with increase in number of cases beginning in May (fall in southern hemisphere) and persisting until October (spring). In addition, there is a considerable increase in the number of positive samples (84/435) in August (winter) and in September (66/435) in most of the analyzed years (Fig. 2b), indicating a seasonality with higher activity during winter in RS.

\section{HAdV detection by age and by gender}

In this study, the 57 samples searched to identify the HAdV species were selected from 435 positive samples from 28,524 patients. Cases of HAdV represent $4.36 \%$ of all respiratory infections occurred in the periods 1996-2004 and 2011-2017 (Table 1). In these periods, respiratory infections for any respiratory virus account for 35\% (9983) of all suspected cases in RS. When analyzing the data per year, 1998 presented the higher frequency (48/238) of cases of respiratory infection by $\mathrm{HAdV}$, representing $20.17 \%$ of all positive respiratory viruses, followed by
2001 (15.86\%), 2004 (12.67\%), and 1996 (12.40\%). The lowest frequency of HAdV cases registered in RS was in $2017(1.17 \%)$.

Demographic characteristics of patients with HAdV species identified are presented in Table 1. Regarding to gender, $20(37.7 \%)$ patients are females and $33(62.3 \%)$ are males. Age ranged from $<1$ to 81 years, noting that most patients were between $<1$ and 1 year old, being measured 19 and 10 patients, respectively. HAdV-B was identified in patients with age ranging from $<1$ to 10 and in patients with 60 and 79 years old. HAdV-C was present in children with age ranging from $<1$ and 4 years, while HAdV-E were in patients ranging from 8 to 81 years old. The two positive samples for HAdV-D were associated with patients aged 1 and 31 years. It is observed that the only year in which respiratory infections were not detected in children was in 2012 (Table 1). From 2013 to 2017, 18 fatalities (Table 2) associated with HAdV occurred: 11 were related to species $\mathrm{B}, 4$ to $\mathrm{C}$, and 2 to $\mathrm{D}$ and 1 remained untyped. It may be observed that in the comparison per year, 2017 was the one with the highest number of deaths; that is, of the 15 patients who presented respiratory infections in that year, 6 had outcome to death (Table 1). Among the 18 fatalities, 5 different types of comorbidities were observed: chronic pneumopathy $(1 / 18)$, chronic cardiovascular disease (3/18), immunodeficiency/immunodepression (3/18), Down's syndrome (1/18), and obesity (2/18). In addition, of the 18 patients who died, $11(61 \%)$ were younger than 20 years (Table 2). 


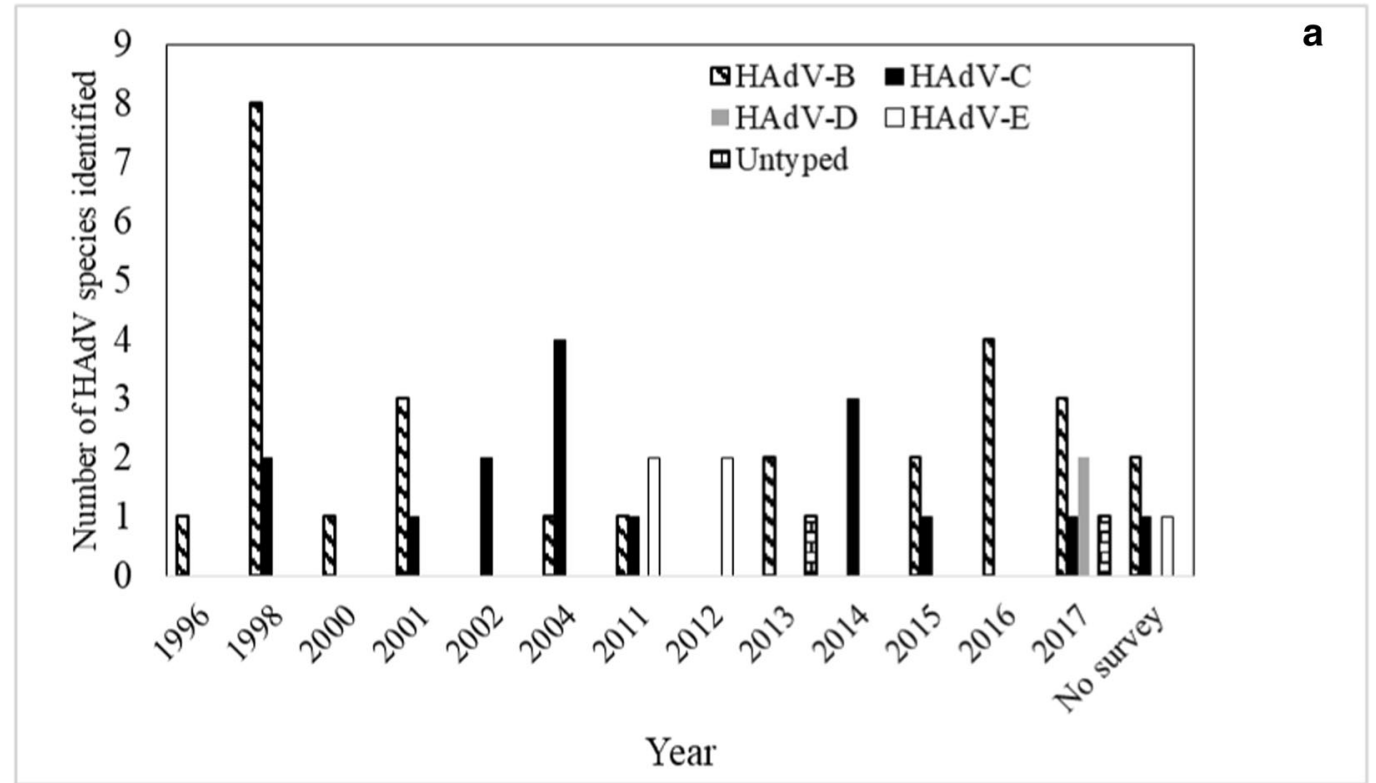

b

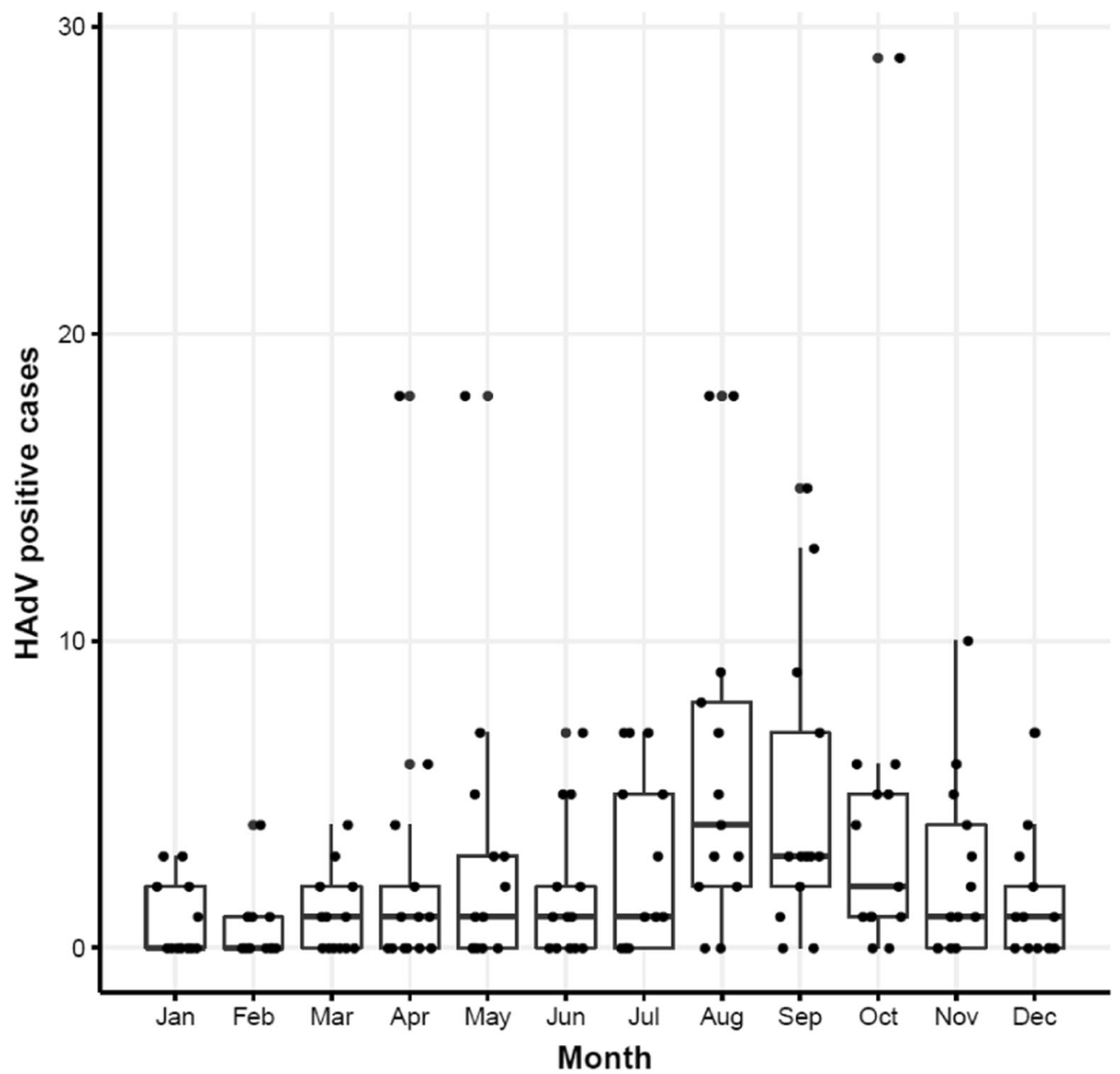

Fig. 2 Total number of cases of patients with respiratory infection associated with Human mastadenovirus (HAdV). a Samples with sequenced. b Seasonality of all $435 \mathrm{HAdV}$ infection cases according to epidemiological weeks in Rio Grande do Sul from 1996 to 2017 


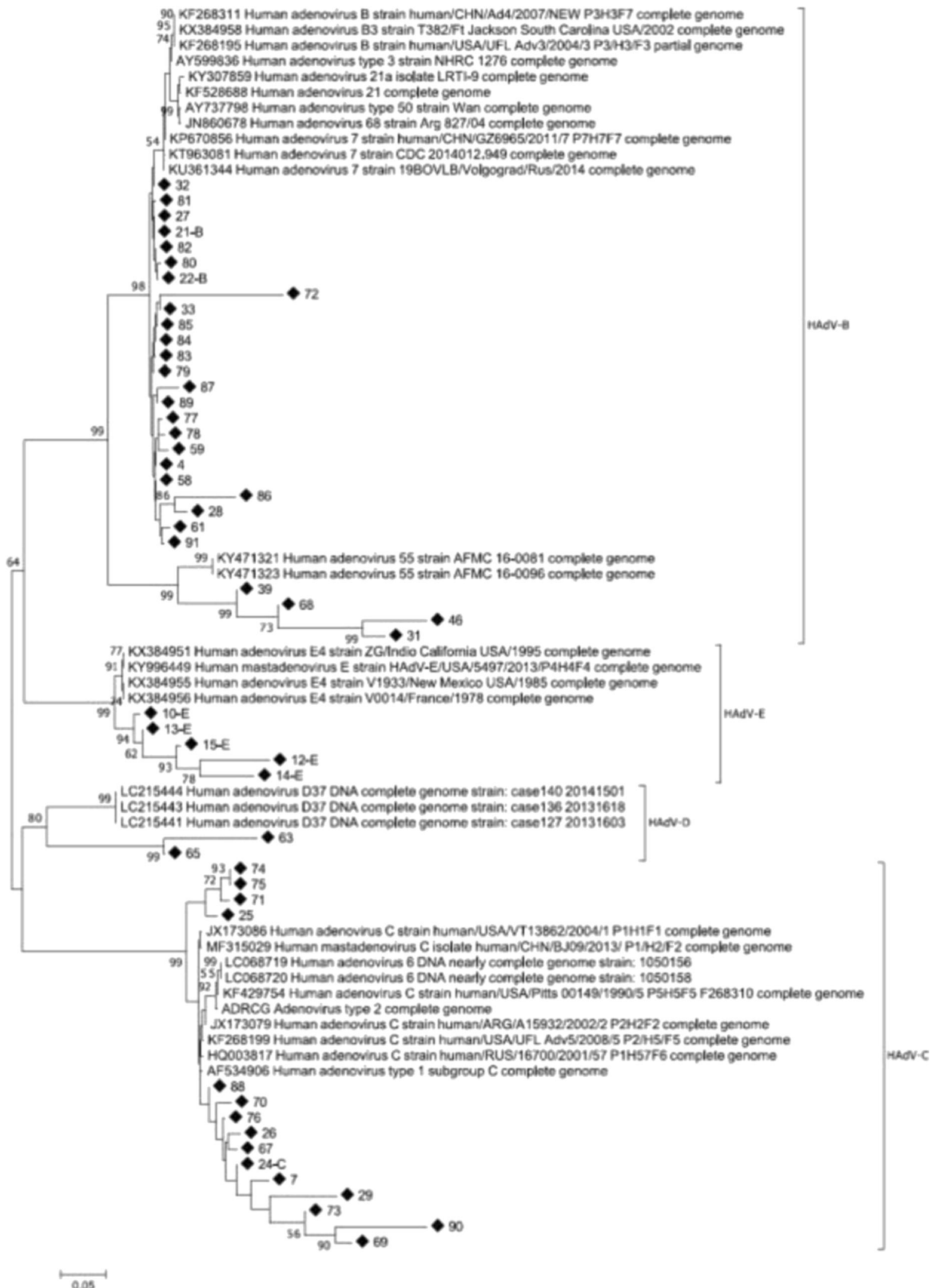

Fig. 3 Phylogenetic tree with the identification of four Human mastadenovirus species (HAdV-B, HAdV-C, HAdV-D, and HAdV-E) from samples of patients with respiratory infection. $\downarrow$ Positive samples sequenced. Bootstrap values represented in the branches are those above 50 in 500 replications 


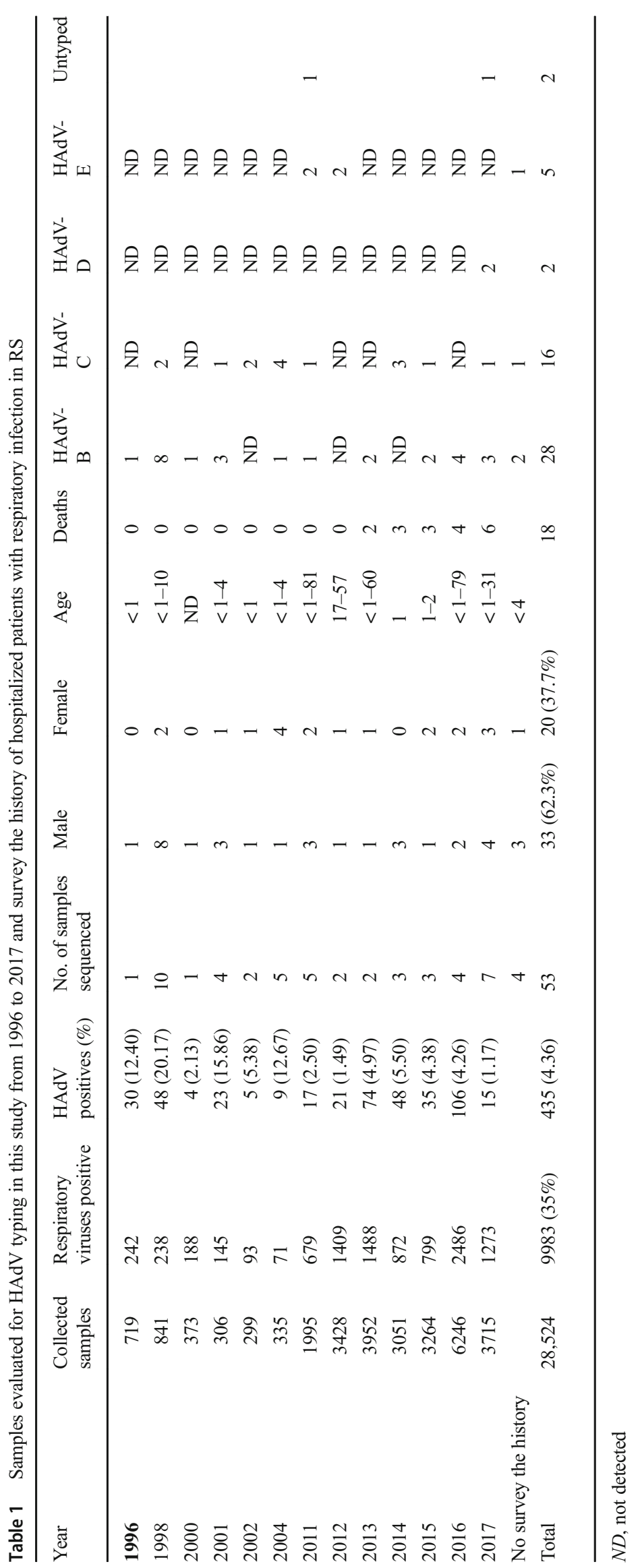


Table 2 Characteristics of patients with respiratory infection who died (gender, age, and presence or not of any comorbidity) in RS, 2013-2017

\begin{tabular}{|c|c|c|c|c|}
\hline \multirow[b]{2}{*}{ Gender } & \multirow[b]{2}{*}{ Male } & \multirow{2}{*}{$\begin{array}{l}\text { No comorbidity } \\
6\end{array}$} & \multirow{2}{*}{$\begin{array}{l}\text { Comorbidity } \\
3\end{array}$} & \multirow{2}{*}{$\begin{array}{l}\text { Total } \\
9\end{array}$} \\
\hline & & & & \\
\hline & Female & 4 & 5 & 9 \\
\hline \multicolumn{5}{|c|}{ Age range } \\
\hline & $<6$ months & 2 & & \\
\hline & 6 to 11 months & 2 & 1 & \\
\hline & 1 year & 2 & & \\
\hline & 2 to 4 years & 1 & 1 & \\
\hline & 5 to 9 years & & 1 & \\
\hline & 10 to 19 years & 1 & & \\
\hline & 20 to 29 years & 1 & 1 & \\
\hline & 30 to 39 years & & 2 & \\
\hline & 40 to 49 years & 1 & & \\
\hline & $\geq 60$ years & & 2 & \\
\hline & Total & 10 & 8 & 18 \\
\hline
\end{tabular}

*Comorbidities: chronic pneumopathy (1), chronic cardiovascular disease (3), immunodeficiency/immunodepression (3), Down's syndrome (1), obesity (2)

\section{Discussion}

The present study identified HAdV species involved in cases of respiratory infection in hospitalized patients in RS. A greater detection was obtained for B $(28 ; 49.1 \%)$, followed by C $(16 ; 28 \%)$, and these species were identified during practically the entire evaluated period, fact also observed in other studies $[10,12,14,15]$. However, in relation to the detection of species $\mathrm{D}$ and $\mathrm{E}$, it is observed that they were present only in some specific periods (species E in 2011 and 2012 and species $\mathrm{D}$ only in 2017) and in low frequency when compared with the other species. Similar results were also described by studies from the northeast region of Brazil in which they detected HAdV-E only in 2007, 2008, and 2010 years [13]. Few studies report the occurrence of HAdV-D associated with respiratory infection, and when present, it is also at a low frequency in relation to the other groups. Work done in Milan during 2013 and 2014 showed the occurrence of the D-26 species in only one case (1.7\%) [15]. Thus, in cases of respiratory infections, it can be stated that species D presents seasonal behavior since no predominance of detection is observed over the years. Another factor that can be considered about this species is tropism because the respiratory system is not the preferred site of infection. HAdV-D mainly causes ocular disease, including epidemic keratoconjunctivitis [20].

In the present study, we have shown that the respiratory infections caused by HAdV occurred along the years with increase in the seasonality in fall, winter, and spring in Rio Grande do Sul. Studies described in the literature show that in the spring, autumn, and winter seasons, there is an increase in the number of cases of respiratory infections, especially in southern Brazil, a region with humid subtropical climate (or temperate) with sudden drops in temperature in winter $[4,5]$. Studies about hospitalizations due to respiratory infection in the state of Rio Grande do Sul show that in the cold months there is an increase in the number of hospitalizations [5]. Among the factors that may explain this seasonal behavior are the transitions from autumn to winter and from winter to spring, seasons in which there are changes in temperature and humidity. In addition, outbreaks of influenza occur between the months of May and August [4].

Although respiratory infections caused by HAdVs may affect all ages, in the present study, it was observed that the peak of illness occurred in children under 1 year, and this fact is also described by other studies in the literature [10,13-15]. These results may possibly be due to factors such as the immaturity of the immune system associated with the smaller caliber of the airways $[10,21]$. In comparison by gender, the majority $(56.6 \%)$ of respiratory infections associated with the presence of HAdV occurred in male patients. Some studies show similar results $[10,14]$ including research in the northeastern region of Brazil [13]. HAdVs are one of the major causes of respiratory disease, and although most infections caused are asymptomatic, fatal infections can also occur. In this work, a mortality rate of $6.47 \%$ (18/278) was measured among the cases of patients with acute respiratory infection during 2013-2017. These values are higher when compared with data from the USA, where a total of 136 inpatients, 3.7\% (5) died, on the other hand, is lower when compared to Taiwan results, where $12.5 \%$ (4) died $[10,12]$. The HAdV species associated with the deaths were 11 related to species B, 4 to $\mathrm{C}$, and 2 to $\mathrm{D}$ and 1 remained untyped. Data from the literature shows that HAdV-B3 and B7 may contribute to a severe infection and high mortality rate, as well as B7 is also associated with pneumonia [22-24].

In conclusion, we can affirm that in regard to the results presented, circulation of HAdV species D and E varied over the years, but species $\mathrm{B}$ and $\mathrm{C}$ were present throughout the evaluated period in hospitalized patients in RS. This is the first time that HAdV species are identified in RS. In addition, respiratory infections by HAdV affect children mainly. The identification of HAdV species is fundamental to prevent the transmission of diseases and the occurrence of outbreaks, especially in children under 1 year old.

Acknowledgments We would like to thank the financial and structural support from University Feevale, the Brazilian National Council for Scientific Development (CNPq), and the LACEN-RS (Central Laboratory of Public Health of Rio Grande do Sul state) for giving away the samples. To Dr. Marcelo F. C. Gomes, Programa de Computação Científica da Fundação Oswaldo Cruz (PROCC/FIOCRUZ-RJ) for help in generation of graphics. 


\section{References}

1. Braga A, Conceição GM, Pereira LA, Kishi H, Pereira JC, Andrade MF, Gonçalves FLT, Saldiva PHN, Latorre MRDO (1999) Air pollution and pediatric respiratory hospital admissions in São Paulo, Brazil. J Environ Med 1:95-102. https://doi.org/10.1002/(SICI) 1099-1301(199904/06)1:2<95::AID-JEM16>3.0.CO;2-S

2. Shi T, McLean K, Campbell H, Nair H (2015) Aetiological role of common respiratory viruses in acute lower respiratory infections in children under five years: a systematic review and meta-analysis. J Glob Health 5:129-138. https://doi.org/10.7189/jogh.05.010408

3. Shi T, McAllister DA, O’Brien KL et al (2017) Global, regional, and national disease burden estimates of acute lower respiratory infections due to respiratory syncytial virus in young children in 2015: a systematic review and modelling study. Lancet 390:946958. https://doi.org/10.1016/S0140-6736(17)30938-8

4. Godoy DV, Dal Zotto C, Bellicanta J, Weschenfelder RF, Nacif SB (2001) Doenças respiratórias como causa de internações hospitalares de pacientes do Sistema Único de Saúde num serviço terciário de clínica médica na região nordeste do Rio Grande do Sul. J Pneumol 27:193-198. https://doi.org/10.1590/S010235862001000400005

5. Mota LMM (2009) Perfil das hospitalizações por doenças respiratórias no sistema único de saúde em Porto Alegre. Boletim de Saúde 23:23-30 http://www.boletimdasaude.rs.gov.br/ conteudo/1443/perfil-das-hospitaliza\%C3\%A7\%C3\%B5es-pordoen $\% \mathrm{C} 3 \% \mathrm{~A} 7$ as-respirat $\% \mathrm{C} 3 \% \mathrm{~B} 3$ rias-no-sistema-\% $3 \%$ BAnico-de-sa\%C3\%BAde-em-porto-alegre

6. Filho EBS, Silva AL, Santos AO, Dall'acqua DSV, Souza LFB (2017) Infecções Respiratórias de Importância Clínica: uma Revisão Sistemática. Rev FIMCA 4:7-16 http://www.fimca.com. br/arquivos_revista/2-Filho_RevFIMCA_2017.pdf

7. Ison MG (2006) Adenovirus infections in transplant recipients. Clin Infect Dis 43:331-339. https://doi.org/10.1086/505498

8. Moura PO, Roberto AF, Baldacci NHE, Ejzenberg SEVB, Perrini P, Stewien KE, Durigon EL, Mehnert DU, Hársi CM (2007) Molecular epidemiology of human adenovirus isolated from children hospitalized with acute respiratory infection in São Paulo, Brazil. J Med Virol 79:174-181. https://doi.org/10.1002/jmv.20778

9. Kandel R, Srinivasan A, D’Agata EMC, Lu X, Erdman D, Jhung M (2010) Outbreak of adenovirus type 4 infection in a long-term care facility for the elderly. Infect Control Hosp Epidemiol 31:755-757. https://doi.org/10.1086/653612

10. Cheng JL, Peng C, Chiu N, Weng L, Chiu Y, Chang L, Huang DTN, Huang F, Liu CP, Chi H (2017) Risk factor analysis and molecular epidemiology of respiratory adenovirus infections among children in northern Taiwan, 2009-2013. J Microbiol Immunol 50:418-426. https://doi.org/10.1016/j.jmii.2015.08.006

11. Lee J, Choi EH, Lee HJ (2010) Comprehensive serotyping and epidemiology of human adenovirus isolated from the respiratory tract of Korean children over 17 consecutive years (1991-2007). J Med Virol 82:624-631. https://doi.org/10.1002/jmv.21701

12. Scott MK, Chommanard C, Lu X, Appelgate D, Grenz L, Schneider E, Gerber SI, Erdman DD, Thomas A (2016) Human adenovirus associated with severe respiratory infection, Oregon, USA, 2013-2014. Emerg Infect Dis 22:1044-1051. https://doi. org/10.3201/eid2206.151898
13. Pereira SAR, Florêncio CMGD, Marinheiro JC, Hársi CM, Moura FEA (2016) Adenoviruses and acute respiratory infections in children living in an equatorial area of Brazil. Epidemiol Infect 144: 355-362. https://doi.org/10.1017/S0950268815000916

14. Chen Y, Liu F, Wang C, Zhao M, Deng L, Zhong J, Zhang Y, Ye J, Jing S, Cheng Z, Guan Y, Ma Y, Sun Y, Zhu B, Zhang Q (2016) Molecular identification and epidemiological features of human adenoviruses associated with acute respiratory infections in hospitalized children in southern China, 2012-2013. PLoS One 11:1-14. https://doi.org/10.1371/journal.pone.0155412

15. Esposito S, Zampiero A, Bianchini S, Mori A, Scala A, Tagliabue C, Sciarrabba CS, Fossali E, Piralla A, Principi N (2016) Epidemiology and clinical characteristics of respiratory infections due to adenovirus in children living in Milan, Italy, during 2013 and 2014. PLoS One 11:1-13. https://doi.org/10.1371/journal.pone. 0152375

16. Li Y, Ge X, Zhang H, Zhou P, Zhu Y, Zhang Y, Yuan J, Wang LF, Shi $Z$ (2010) Host range, prevalence, and genetic diversity of adenoviruses in bats. J Virol 84:3889-3897. https://doi.org/10.1128/ JVI.02497-09

17. Saitou N, Nei M (1987) The neighbor-joining method: a new method for reconstructing phylogenetic trees. Mol Biol Evol 4:406-425. https://doi.org/10.1093/oxfordjournals.molbev.a040454

18. Kimura M (1980) A simple method for estimating evolutionary rate of base substitutions through comparative studies of nucleotide sequences. J Mol Evol 16:111-120. https://doi.org/10.1007/ BF01731581

19. Tamura K, Peterson D, Peterson N, Stecher G, Nei M, Kumar S (2011) MEGA5: molecular evolutionary genetics analysis using maximum likelihood, evolutionary distance, and maximum parsimony methods. Mol Biol Evol 28:2731-2739. https://doi.org/10. 1093/molbev/msr121

20. Robinson CM, Shariati F, Zaitshik J, Gillaspy AF, Dyer DW, Chodosh J (2009) Human adenovirus type 19: genomic and bioinformatics analysis of a keratoconjunctivitis isolate. Virus Res 139: 122-126. https://doi.org/10.1016/j.virusres.2008.10.001

21. Salvi S (2007) Health effects of ambient air pollution in children. Paediatr Respir Rev 8:275-280. https://doi.org/10.1016/j.prrv. 2007.08.008

22. Lai CY, Lee CJ, Lu CY, Lee PI, Shao PL, Wu ET, Wang C, Tan B, Chang H, Hsia S, Lin J, Chang L, Huang Y, Huang L (2013) Adenovirus serotype 3 and 7 infection with acute respiratory failure in children in Taiwan, 2010-2011. PLoS One 8:1-7. https://doi.org/ 10.1371/journal.pone.0053614

23. Yamamoto D, Okamoto M, Lupisan S, Suzuki A, Saito M, Tamaki R, Tandoc A, Mercado E, Sombrero L, Olveda R, Oshitani H (2014) Impact of human adenovirus serotype 7 in hospitalized children with severe fatal pneumonia in the Philippines. Jpn J Infect Dis 67:105-1010. https://doi.org/10.7883/yoken.67.105

24. Tang L, Wang L, Tan X, Xu W (2011) Adenovirus serotype 7 associated with a severe lower respiratory tract disease outbreak in infants in Shaanxi Province, China. Virol J 8:1-7. https://doi. org/10.1186/1743-422X-8-23

Publisher's note Springer Nature remains neutral with regard to jurisdictional claims in published maps and institutional affiliations. 